\title{
Beyond Ethnic Tidbits: Toward a Critical and Dialogical Model in Multicultural Social Justice Teacher Preparation
}

\author{
Christina Convertino \\ University of Texas at EI Paso \\ U. S. A.
}

ABSTRACT: This praxis article outlines the value of using a critical and dialogical model (CDM) to teach multicultural social justice education to preservice teachers. Based on practitioner research, the article draws on the author's own teaching experiences to highlight how key features of CDM can be used to help pre-service teachers move beyond thinking about multicultural education as ethnic tidbits. Illustrative examples of CDM-in-use demonstrate that learning about multicultural social justice education is a social and developmental process that requires teacher educators to scaffold complex ideas by using dialogical approaches to learning that incrementally build on emergent and shared knowledge.

KEYWORDS: critical, dialogical, teacher preparation, social justice, practitioner inquiry

Obstacles to Multicultural Social Justice Education

Features of a Critical and Dialogical Model

Making Adjustments with Practitioner Research

A Crucial Bottleneck

The Value and Challenges of a Critical and Dialogical Model

Scaffolding a Critical and Dialogical Model

Final Thoughts

Notes

References

Author Contact

In Profoundly Multicultural Questions (2003), Sonia Nieto differentiates "ethnic tidbits" from multicultural social justice education. Foundational scholarship in multicultural education describes how the field has evolved to represent very different sets of ideas and approaches (Banks, 2013; Grant \& Sleeter, 2007, 2013). Four fundamental practices distinguish multicultural social justice education (Grant \& Sleeter, 2013). First, multicultural social justice education uses democratic practices to facilitate teaching and learning (Mthethwa-Sommers, 2014; Olser \& Starkey, 2005). Second, multicultural social justice education teaches students to analyze structural inequalities in their own lives (Grant \& Sleeter, 2013). Third, multicultural social justice education fosters participatory democracy to change unequal social structures (Grant \& Sleeter, 2013; Mthethwa-Sommers, 2014). Finally, multicultural social justice education 
goes beyond a single group approach (Grant \& Sleeter, 2013) to promote the intersectionality ${ }^{1}$ and multiplicity of identities (Osei-Kofi, 2013).

In contrast to multicultural social justice education, ethnic tidbits represent mainstream approaches to multicultural education, which typically incorporate limited examples of "ethnic heroes/heroines and discrete cultural artifacts into the curriculum" (Banks, 2013, p. 184). This approach, also referred to as an additive or tourist-based approach (Banks, 2013), differs from multicultural social justice education in two primary ways: (a) it does not challenge educators to examine how their own social location within a highly stratified society shapes their teaching praxis (Nieto, Bode, Kang, \& Raible, 2008) and (b) it does not aim to change the status quo (Mthethwa-Sommers, 2014).

As a White female social justice teacher educator in the sociocultural foundations of education, a central focus in my own teaching praxis involves (re)thinking how to cultivate learning opportunities with pre-service teachers to foster a critical understanding of the distinction between ethnic tidbits and multicultural social justice education. In this praxis article, I draw on crucial teaching moments to highlight how I discovered the value of using a critical dialogical model (CDM) to address this distinction. To contextualize the broader potential of CDM to teacher preparation, I begin this article by describing some obstacles to multicultural social justice education. Following this, I outline theoretical features of CDM that I think are most relevant to teaching multicultural social justice education. Lastly, I provide examples from my own teaching praxis to demonstrate how I discovered the value and the limitations of CDM to multicultural social justice education.

\section{Obstacles to Multicultural Social Justice Education}

The "demographic divide" refers to the growing racial, socioeconomic, linguistic, cultural, and gender gap between the predominantly White, female, middle-class, monolingual teaching force and the racially, ethnically, linguistically, culturally, and socioeconomically diverse students attending K-12 public schools throughout the United States (Howard, 2010, p. 40). While this national trend points to the growing significance of multicultural social justice education to teacher preparation, most teacher education programs and accreditation agencies have not altered coursework to adequately incorporate this approach (Ensign, 2009; Gorski, 2009; LaDuke, 2009). Many programs hold "lofty goals of preparation for teaching diverse students" (Ensign, 2009, p. 169) but make nominal changes to "reflect a multicultural perspective" (Nelson \& Guerra, 2015, p. 72). One way to analyze the obstacles involved in altering teacher preparation programs is to consider how enduring values that shape U.S. public schooling are at cross purposes with a commitment to multicultural social justice education.

The knowledge, practices, and languages that diverse students bring to $\mathrm{K}$ 16 classrooms in the United States are often viewed as deficits that need to be 
remediated (Valencia, 2010). Cultural assimilation, meritocracy, and traditional liberal citizenship represent historical and related values that enable a deficit and exclusionary orientation towards diverse students (Dabach \& Fones, 2016; Vickery, 2016). The view that a role of public schooling is to assimilate diverse students based on nation-state principles of meritocracy and traditional liberal citizenship stems in large part from hegemonic metanarratives related to science, progress and knowledge production (Apple, 2004; Giroux, 2011; Montecinos, 2004; Vavrus, 2002). Shome (1999) argues that the metanarratives "privilege and sustain the global dominance of White imperial subjects and Eurocentric worldviews" (p. 108). This raced, gendered, and classed view of knowledge production and the role of schooling erases diverse histories (Salazar, Martinez, \& Ortega, 2016) and subtracts the funds of knowledge that diverse students bring to schools (Dabach \& Fones, 2016; Valenzuela, 1999). Left unchallenged cultural assimilation, traditional liberal citizenship, and meritocracy enable White preservice teachers to resist critically examining how views of "legitimate" knowledge are embedded within the sociopolitical contexts of an exclusionary society (Castro, 2010; DiAngelo \& Sensoy, 2010; LaDuke, 2009; Haviland, 2008; Sleeter, 2008b; Williams \& Evans-Winters, 2005).

In light of the influence that exclusionary values exert on education and teacher preparation, I am interested in understanding how to facilitate teacher preparation that disrupts dominant models of teaching and learning. I think that this is one crucial step in eliminating obstacles to multicultural social justice education. To be clear, I did not always understand what this meant. As a former high school English teacher, I witnessed significant examples of discrimination on the part of teachers and administrators towards students of color, linguistically diverse students, students living in poverty, students with special needs, and LGBTQ students. Based on these observations I knew that I wanted to help future teachers understand the significance of multicultural social justice education; however, I did not initially recognize that a "get the facts out" approach does not help pre-service teachers distinguish between ethnic tidbits and multicultural social justice education (Hill, 2000).

The initial resistance from pre-service teachers ${ }^{2}$ to my use of "evidence" and "facts" to teach threshold concepts helped me to understand the value of a more social and developmental approach (Gorski, Osei-Kofi, Zenkov, \& Sapp, 2013). Threshold concepts are disciplinary "cognitive building blocks," from which students are able to incrementally develop deeper understandings of the meaning and connections between related concepts and ideas (Gorski et al., 2013 , p. 4). For example, institutional oppression is a threshold concept in multicultural social justice education; when students understand this concept, they are better able to make connections between the roles of racism, homophobia, abilitism, classicism, sexism, and tracking in educational settings. In what follows, I describe theoretical features of CDM in order to highlight the relevance of CDM to teaching threshold concepts found in multicultural social justice education. 


\section{Features of a Critical and Dialogical Model}

Sociocultural theory (Bakhtin, 1986; Vygotsky, 1978; Wells, 1999a, 1999b, 2007, 2009), intergroup dialogue ${ }^{3}$ (Nagda \& Gurin, 2007; Sorensen, Nagda, Gurin, \& Maxwell, 2009), and critical consciousness (Freire, 1999) are complementary views of learning that inform my understanding and use of CDM. Although they are theoretically and methodologically distinct, each lens emphasizes dialogical meaning-making that attends to the role of power in knowledge production and social life.

By bringing together these sympathetic lenses, I view CDM as a pedagogical framework to structure purposeful social interaction that creates shared knowledge through the "process of discovering what I think and want to say and through the feedback I receive in the responses of my interlocutors" (Wells, 2009, p. 269). This view of teaching and learning is further informed through the intentional use of intergroup dialogue to promote

an interactive communication style, where ideas and perspectives are presented but students are encouraged to use active listening and to ask questions of their peers to promote increased understanding for how and why identity and socialization have shaped students' perspectives on the world. (Sorensen et al., 2009, p. 13)

Critical consciousness further extends the view of dialogue to a political one. What this means is that I use CDM as a pedagogical framework to facilitate shared meaning-making wherein "dialogue as a process of learning and knowing must always involve a political project with the objective of dismantling oppressive structures and mechanisms prevalent both in education and society" (Freire \& Macedo, 1995, p. 380). In total, I draw on views of learning from sociocultural theory, intergroup dialogue, and critical consciousness to facilitate content learning and structured interaction that encourages students to understand content through guided self-reflection, critical communication and alliance building (Sorensen et al., 2009).

I also understand that instructors who use CDM need to pay particular "attention to the dynamics of classroom discourse" (Wells, 2009, p. 269) to ensure multiple and diverse forms of student participation and to examine what assumptions are being made as well as which identity perspectives are valued and devalued (Cochran-Smith, 2000). For example, I use CDM as a guiding framework when I invite students to think about how "their usage of 'air time' relates to their identities and the privileges afforded by those identities" (Sorensen et al., 2009, p. 17). This requires that I too must continuously engage in my own process of critical self-reflection to examine how I limit and facilitate inclusion of multiple student voices and perspectives.

Because CDM uses "both identity and structural inequality as a framework to examine diverse perspectives... and opportunities for collaborative action" 
(Sorensen et al., 2009, p. 14), it can be a slippery slope to navigate. CDM can also be an uncomfortable process since there are no predefined or quantifiable outcomes. At the same time, CDM offers a valuable pedagogical alternative to help pre-service teachers learn threshold concepts found in multicultural social justice education. To illustrate some of the possibilities and limitations to implementing CDM-informed practices in teacher preparation coursework, I next highlight how I first discovered CDM in my own teaching experiences.

\section{Making Adjustments with Practitioner Research}

Encompassing multiple histories and different epistemologies, practitioner inquiry is a research genre grounded in a theory of action and practitioner knowledge aimed at transforming teaching and learning (Cochran-Smith \& Lytle, 2009). With a focus on social practice, practitioner research involves an ongoing and iterative process of problematizing current educational practices and arrangements by examining how knowledge is constructed and used in educational settings and then acting on that information by implementing change. In my own teaching praxis, I engage in practitioner research to question and reflect on how my pedagogical practices facilitate and/or limit students' understandings of multicultural social justice education. This continual process of inquiry requires that I use a "critical habit of mind" (Cochran-Smith \& Lytle, 2009, p. 120) to make informed decisions about what changes I need to make in the contexts of my teacher preparation courses and then to repeat the process of questioning and reflecting and acting to further transform my educational practice and knowledge.

For the remainder of this article, I illustrate how I engaged practitioner research to question, observe, and act on my own teaching praxis in the contexts of two teacher preparation courses. Primary data sources included my field notes and reflections of whole-class discussions, course syllabi, course readings, and student assignments that I had consent to use: e.g., student journals, reflective reading responses, and digital stories. Using an interpretive analytical lens (Emerson, Fretz, \& Shaw, 2011), I conducted multiple rounds of open and focused coding to develop descriptive codes (Saldaña, 2013) that shaped three questions. The first question is "How does my current teaching praxis create bottlenecks?" Bottlenecks are "a sort of collective comprehension backup" that occur when instructors are unable to successfully facilitate teaching and learning of threshold concepts (Gorski et al., 2013, p. 1). The second question is, "What theories of learning reflect a social and developmental approach to teaching threshold concepts?" And the third question is, "What pedagogical adjustments do I need to make to facilitate teaching and learning opportunities that reflect a social and developmental approach?"(Gorski et al., 2013). These three questions that emerged from data analysis guide how I view and use CDM to teach threshold concepts, a process that is continuously unfolding and changing. As one example of how I initially engaged with this process, I next describe a crucial 
bottleneck that led me to uncover the value of CDM to teaching threshold concepts.

\section{A Crucial Bottleneck}

A crucial bottleneck occurred while I was teaching a required course for secondary education majors that focused on multicultural schools and literacy across all content areas (for the sake of clarity, hereafter I will refer to this course as Course I). Of the 25 students in this course, the majority (20) were White and monolingual. There were five Latino students, all of whom were bilingual. Out of the entire group, there was a relatively even distribution between females and males.

At the beginning of the semester, I wanted to gain a sense of how the preservice teachers in Course I thought about the relationship between their future role as secondary educators and multicultural education. During our first class meeting, I explained that weekly journal writings were a primary assignment and a significant portion of their grade. I also informed them that the journal was intended to encourage reflection on course content. Following the first class meeting, I assigned several readings to introduce principles of multicultural social justice education. I also assigned the first journal writing assignment using the following prompt: What is the significance of learning about diversity and multicultural education to your future teaching practice? This excerpt from a White, male pre-service teacher's journal provides an example of how many of the White students in Course I initially thought about multicultural education:

I guess I am really just fed up with all the theories and research findings, which never lead to concrete practices that we can implement in the classroom. The fact of the matter is that we cannot learn everyone's native language or culture so that we can teach them effectively. If a student has a problem identifying with a teacher because of cultural differences then that student needs to find help.

Like many of the responses from White students in Course I, this student's response reduced multicultural education to ethnic tidbits in ways that reflected a hegemonic metanarrative of White Eurocentric supremacy and positioned the cultural "other" within a deficit framework.

As the semester progressed, a majority of the White pre-service teachers in Course I continued to use the reflective journal as a platform to air their complaints and insist that I provide them with methods to teach ethnic tidbits to their future students. In an effort to make a distinction between ethnic tidbits and multicultural social justice education, I introduced the concept of institutional racism. I did this by drawing a statistical comparison between the educational opportunities and outcomes of different racial groups; essentially, I used a "get the facts out" approach to teach this extremely complex concept. At the time, I reasoned that a "get the facts out" approach would provide irrefutable evidence 
to support the relevance of multicultural social justice education and to counter the resistance from White students.

When I presented the statistics to the class, several of the five Latino/a students nodded their heads, a gesture that I interpreted as an indication of agreement and/or recognition. In contrast, several White students protested on the basis of reverse discrimination and meritocracy. For example, one female student stated, "All Americans have equal opportunities and to focus on racial differences in terms of resources, representation, and access to higher education is racist." In order to better gauge individual understanding of the concept, I asked the class to reflect on the statistical comparison in their journals. The following journal excerpt from one White male student represented the threshold concept of colorblindness, which posits that talking about race is racist.

A common culture in America is emerging while people cling to bits of their family's culture. What your skin color looks like has almost nothing to do with your culture and who you are.... I am offended by the label white, which has no meaning. Why can't we all just be Americans?

Other White pre-service teachers cited personal examples of what they called "reverse discrimination": for example, not receiving a scholarship because all of the scholarships went to "minority students" or being left out of graduate student information meetings because they were exclusively for "minority students." In contrast, several Latino/a pre-service teachers, who were silent (or slienced) in the context of proceeding class discussions, wrote in their journals about their frustrations with the White pre-students' responses.

In spite of my intention to facilitate an understanding of the distinction between ethnic tidbits and multicultural social justice education, my use of a "get the facts out" approach created a crucial bottleneck. This became most apparent to me when a White female student announced (during a subsequent class discussion), "If there really was a problem, then 'people' could speak up and say what they needed to say [and] no one was stopping them." In that moment I knew that I had to respond to the bottleneck but I was at a loss on how to do it. With significant trepidation, I looked at the student and asked her, "Wait. Look around you. Who are the 'people' talking right now in this room? Does the fact that only White students are talking — have been talking since I introduced this topic-mean that there is no problem or might that be part of the problem?" After a silent, and what I felt was a tense, pause I dismissed the class in order to give myself some time to think about what had happened and what needed to change.

In reflecting on the bottleneck, I realized that my use of "evidence" to teach about systemic discrimination was the wrong approach. In the following class meeting, I explained that the classroom discourse did not reflect multiple perspectives and that this had to change. I briefly reminded them of Vygotsky's theory that learning and knowledge are socially and culturally constructed; I knew that they had been introduced to these ideas in some of their other teacher preparation courses. I also talked about the fact that schools typically do not 
value or reflect multiple ways of knowing. I then explained that I would be changing how I had been teaching by moving from a transmission-based approach to a critical and dialogical one, which meant that they would also have to change how they were learning. To do this, I told them that they would need to use their journals and our classroom discussions as learning opportunities to (a) reflect on the idea that "how we are positioned in terms of race and power...has a lot to do with what we see or want to see, and what we are not able to see" (Cochran-Smith, 2000, p. 161); (b) create dialogue based on diverse voices, perspectives and experiences; and (c) explore how knowledge is socially negotiated and constructed in contrast to the idea that there is a single right answer.

To ensure inclusion of multiple perspectives and shared meaning-making in our classroom discussions, I also decided that I would select journal entries that I thought would advance the classroom discourse and with student consent read the entries out loud in class. ${ }^{4}$ In response to entries read out loud, students were instructed to refrain from responding immediately, listen actively, and attempt to make connections between journal entries and course readings. Subsequently, I would read responses to previously read journal entries that served to expand the classroom discourse. From the outset, I clarified that what I meant by expanding the conversation was not the same as reaching agreement but rather sustaining a critical and reflective dialogue that pushed us to think about topics in new and deeper ways. The following sequence of examples is meant to illustrate my initial use of CDM in Course I.

\section{The Value and Challenges of a Critical and Dialogical Model}

A week or two had passed since I had made a formal shift from a "get the facts out approach" to a more critical and dialogical one. I had asked the preservice teachers to respond to several readings on bilingual education in their journals. During a class meeting, I read from the journal of a Latina pre-service teacher who described her negative experiences as an English Language Learner with an elementary school teacher. Based on what I read from the student's journal, a robust and inclusive class discussion emerged about the significant racial and economic segregation that characterized local school districts serving Latino/a students. In response to the high levels of diverse student participation, I chose to replace scheduled course readings with several readings that focused on how teaching methods contribute to institutional racism and educational inequities. In response to one of the readings, Beyond the Methods Fetish: Toward a Humanizing Pedagogy (Bartolome, 1994), another Latina pre-service teacher responded in her journal:

In the Bartolome article, issues of how minorities are being cheated out of equal education was brought up. I very much believe this because I experienced this myself, unfortunately. Many individuals in our class may refuse to look at the truth but ignoring the issue does not go away.... 
However, I do not think reverse discrimination is the answer or should be allowed. I don't care who or what the individuals' status is. No one should experience discrimination. I've experienced it many times and I do not wish it upon my worst enemy.

Counterstorytelling (Delgado, 2000) is a method of telling stories based on critical race theory (Solorzano \& Yosso, 2002) that aims to counter hegemonic metanarratives of race, power, identity, and unequal social relations. In the preceding example, the student used a form of counterstorytelling to explore her own positionality relative to the topics of institutional racism and educational inequities that challenged dominant representations of the status quo in society and within course discussions. Her use of counterstorytelling also reflected the following features of CDM: (a) the role of social interaction to meaning-making; (b) the value of intergroup dialogue to understanding how positionality shapes different ideas and perspectives about the world; and (c) the role of dialogue to generate the critical consciousness needed to dismantle oppressive educational and social structures.

While the prior example points to the potential value of CDM, I also worried that my use of journal entries to promote a CDM approach to teaching and learning threshold concepts created serious pitfalls. In particular, I worried that I had risked "using some people's education in the service of others' education" (Cochran-Smith, 2000, p. 174); reified marginalization (Blackburn, 2013 , p. 61) rather than disrupted it; and selectively, even selfishly, showcased stories that spoke to my passion for social justice at the expense of greater levels of intergroup dialogue between the students. For example, one of the White male students in Course I wrote the following in response to the Latina student's counterstory that I had read in the prior class meeting:

I was disappointed last Tuesday when you read the person's journal that was speaking about their literacy background and they expressed the fact that no one cared except for you, the teacher. (...) I was fascinated with everyone's story! (...). I feel they allowed the "normal white American" to enter the school lives of a minority and experience the difficulties that these students have had.

There were other similar examples, where several White pre-service teachers wrote in their journals, that a Latina pre-service teacher had unfairly judged her elementary teacher because she was White. In turn, some of the Latino/a preservice teachers expressed concern in their journals that they might have offended their White peers in the class or, conversely, they felt no one was really listening to the journal readings that reflected counterstorytelling.

In sum, I think that my first efforts to use CDM instructional strategies were more of a bottleneck intervention that came too late in the semester. However, using the three questions that emerged from the practitioner research analysis, I identified what pedagogical changes I needed to make to move from a simplistic understanding of CDM as a roadmap to navigate bottlenecks to an appreciation for CDM as a conceptual framework to shape instructional strategies that were 
not only social but also developmental. More specifically, as a result of the analysis, I gained three insights. First, I acknowledged that how I taught complex ideas had to reflect the content I was teaching. In other words, I had to do more than just talk about teaching, learning, and knowledge production as social and cultural phenomenon in the abstract; I had to embody and model it in my teaching praxis. Second, I realized that I had confused my own passion and commitment for socially just education as critical pedagogical praxis (for more on how passion shapes pedagogical responses to bottlenecks, see Blackburn, 2013). In reflecting on Course I, I developed a better sense of how my passion often turned into impatience with White students during whole class discussions. This led me to an understanding that, if I really wanted to foster social change, then I would have to use my passion to be a better teacher educator, one who understood that "critical consciousness cannot be imposed on the students, nor is it immediate; it is both developmental and cyclical" (Nagda \& Gurin, 2007, p. 36). Relatedly, the third insight was that I needed to build rapport with each individual student and to scaffold my use of CDM-informed instructional strategies in order to "help students reveal to themselves where they are in their thinking, a crucial step on the path toward deeper consciousness" (Gorski, 2013, pp. 89-90). In total, these insights informed the following pedagogical adjustments that I made in my use of CDM-informed instructional practices.

\section{Scaffolding a Critical and Dialogical Model}

As a stand-alone multicultural education course in early childhood education, Course II offered an important opportunity to further develop my use of CDM to teach multicultural social justice threshold concepts based on what I had learned from Course I. Course II was comprised of a majority of White students (18), five Latina students, an Asian American student, an African American student, and a Native American student. All students were female.

In thinking about how I might initially scaffold the use of CDM-informed instructional strategies in Course II, I focused on the dialogical idea of sharing "intersubjectivity (i.e., common understandings) to maintain dialogic conversation and facilitate learning" (Chizhik \& Chizhik, 2005, p. 117). Based on this idea, I developed one of the primary course assignments for Course II, a semester-long annotated bibliography that would be housed on the online course website. In addition to annotating each course reading, pre-service teachers were required to describe how they thought the course reading connected to their future teaching practice. I used features of CDM to guide decisions about the requirements for the annotations in order to foster a discursive space in which each student and I could begin to get to know one another and build a level of trust. I reasoned that the annotations would create a process of shared intersubjectivity based on a back-and-forth dialogue between each student and me. 
Using the online course website, students uploaded weekly annotations to which I provided a weekly response. I limited the content of my weekly responses to questions and comments that showed the students I had read and thought about what they wrote and wanted to better understand the student's process of learning. The weekly online student submission with my weekly response appeared in chronological order over the course of the semester, a feature which I found to be important because it allowed the student and me to observe the emergent development of our ongoing dialogue, thus creating a more shared understanding of the student's learning process.

In keeping with a CDM framework, I chose not to grade students for the content of what they wrote, and I did not provide corrective feedback. However, because I knew that the annotations would be a time-consuming assignment and it was one that I wanted the students to take seriously, I assigned a set number of points per annotation based on timely completion and submission of the required components for each annotation. The annotation assignment as a whole made up $25 \%$ of students' final course grade.

I also designed the annotation assignment so that students were required to complete and submit each weekly annotation one day prior to our weekly faceto-face class meeting. I did this so that I could take a cursory look at the annotations prior to our class meeting in order to get a sense of how students were understanding and thinking about course content presented in weekly readings. Based on my cursory reading of annotations, I would then make pedagogical adjustments to planned in-class CDM-informed activities. For example, when I noticed a pattern of potential bottlenecks to threshold concepts in students' annotations, I often changed the seminar style discussion that I had planned for the class meeting to a set of more applied role-playing activities in which students took turns improvising different roles, e.g., parent, teacher, administrator, student, and grandparent, to address a school-related matter or event. Breaking down a complex threshold concept like parent involvement in this way allowed students an opportunity to work through the idea that teachers and administrators often ignore and devalue diverse forms of parent involvement and that this undermines educational equity. Like the annotations, the applied inclass activities required significant reflection, planning, and preparation.

The online annotations coupled with the experiential in-class activities laid the groundwork for the culminating and final group project, a CDM-informed digital storytelling project. For this project, a central objective was for the preservice teachers to reflect on how their growing awareness of their own social location shaped their views of multicultural social justice education. Accordingly, they were required to complete a "critical life history questionnaire," a set of questions that I developed to scaffold the ongoing process of developing critical consciousness using CDM. The 24-item questionnaire was informed by readings and discussions related to critical family history (Sleeter, 2008a) and funds of knowledge (Gonzaléz, Moll, \& Amanti, 2005) that the students had completed earlier in the semester. Examples of questions included: How do I understand the role of culture in my life growing up? What are the privileges that have informed 
my positionality? What are the obstacles that inform my positionality? In contrast to the journal writing exercise I used in Course I, the questionnaire invited the pre-service teachers to reflect on their own specific experiences and to explain those experiences in relationship to course topics: i.e., culture, privilege, and positionality.

After completing the questionnaire, I assigned pre-service teachers to groups intended to maximize the limited racial, gender, and socioeconomic diversity found in the class. Using their individual responses to the "critical life history questionnaire," each group was charged with the task of creating a single shared digital narrative based on the integration of the multiple life histories represented in the group as a whole. The following example represents one of the ways in which a group of pre-service teachers implemented CDM to create their shared digital story. In the following excerpt from the digital story, a group of three White females and one Latina are pictured in the throes of an unscripted dialogue discussing the theme of their digital story: "What has shaped us?"

White Female 1 (W1): I am definitely one of the White's who doesn't think they have a culture. I fall into that. I still have a difficult time understanding my culture. Never something l've been taught until this class.

White Female 2 (W2): What is sort of limiting of what we do learn in this class is that we're not given the opportunity to talk to diverse people and a lot of us are all similar, I mean we're all women, we're all receiving a college education. I think going out into the world and having these kinds of conversations with people who are different than us is really important and something I definitely learned from class and you are going to meet a lot of resistance.... I don't know why.

Latina Female (L): I think it has a lot to do with colorblindness. I'd say before this class that's how I viewed myself, like "Everybody is the same."

White female $3(W 3)$ : Yea, that is the way to view it. That is what you're engrained to think, like if you're not racist then you don't see it. And we've learned that you need to acknowledge it.

As one of several similar examples of digital stories in Course II, this critical and dialogical exchange between pre-service teachers provides a salient representation of the value of CDM as a conceptual model to teach multicultural social justice education. This example also illustrates the impact of CDMinformed instructional strategies in helping pre-service teachers to acknowledge how positionality, power, and identity shape our views about social inequalities. In addition, the excerpt points to the ways in which one pre-service teacher, in particular, had begun to internalize the critical and dialogical features of CDM to think about how to involve multiple perspectives and experiences beyond the course to enable even greater dialogical meaning-making. Lastly, this example offers an important representation of how a CDM approach can provide instructors with in-depth information and productive student feedback to reflect on what instructional strategies, content, activities, and ideas are effective and where they should focus efforts to make future pedagogical adjustments. This 
finding supports a more emergent and developmental view of teaching multicultural social justice education as well as the idea that "multicultural education must be viewed as an ongoing process" (Banks, 2013, p. 4).

\section{Final Thoughts}

In this article, I have described how I used practitioner inquiry to guide my understanding and use of CDM to teach multicultural social justice education. Although limited in scope, examples from Course I and Course II demonstrated some of the ways in which CDM can be used to shape instructional strategies that help pre-service teachers to distinguish between ethnic tidbits and multicultural social justice education. Examples also highlighted the value of CDM to teaching disciplinary building blocks from which students incrementally develop a deeper understanding of threshold concepts to analyze: (a) how individuals' positionality and social location in a stratified society shape their views and perspectives on social and educational inequalities; (b) how knowledge is socially constructed; and (c) how listening to and incorporating diverse voices and alternate perspectives creates new understandings.

Comparisons between the experiences and activities in Course I and Course II highlighted the importance of scaffolding CDM instructional strategies and activities to reflect a developmental approach to learning complex threshold concepts found in multicultural social justice education. Comparisons between the two courses did account neither for differences in the gender, racial, and ethnic composition of students, nor for differences in the purpose of the two courses; these are important considerations that merit future attention and represent a limitation to this analysis.

Future research on the use of CDM to teach multicultural social justice education would also benefit from exploring how social media, like Facebook pages and online polling, can be leveraged to initiate a dialogical exchange between pre-service teachers and a wider public audience to explore a wider range of perspectives, something I have begun to do in the multicultural social justice courses that I currently teach. Similarly, I have begun to use CDM as a robust pedagogical framework in hybrid and online diversity teacher preparation courses where the opportunities to engage in critical and dialogical ways of teaching, knowing and learning are increasingly more complex. In sum, it is my position that CDM is a valuable pedagogical framework to help pre-service teachers move beyond thinking about multicultural education in terms of ethnic tidbits to understand the importance of multicultural social justice education. 


\section{Notes}

1. Intersectionality is "a theory to analyze how social and cultural categories of identity and oppression are connected" (Blackburn \& McCready, 2009, p. 229).

2. The initial resistance from pre-service teachers that I refer to occurred in teacher preparation courses that I taught after I stopped teaching high school to pursue a doctoral degree.

3. As defined by Sorenson et al. (2009), intergroup dialogue (IGD) courses "bring together members of two different social identity groups ...utilizing a guided and structured model to engage members...in face-to-face interactions with the goals to improve and deepen intergroup communication and relationships, foster intergroup understanding of identity and inequality, and help students develop the skills and commitment to engage in intergroup collaboration" (pp. 12-13). The key principles of IGD include three pedagogical processes-content learning, structured interaction, and facilitative leadership_and four communication processes: engaging self, learning from others, critical reflection, and alliance building.

4. All journal entries were read out loud with student consent. I also left out certain details when I read entries to increase the likelihood that the student's identity would remain anonymous.

\section{References}

Apple, M. (2004). Ideology and curriculum ( $3^{\text {rd }}$ ed.). New York, NY: Routledge.

Bakhtin, M. M. (1986). Speech genres and other late essays ( $2^{\text {nd }}$ ed.). Austin, TX: University of Texas Press.

Banks, J. A. (2013). Multicultural education: Characteristics and goals. In J. A. Banks \& C. A. McGee Banks (Eds.), Multicultural education: Issues and perspectives ( $8^{\text {th }}$ ed.) (pp. 3-32). Hoboken, NJ: Wiley.

Bartolome, L. (1994). Beyond the methods fetish: Toward a humanizing pedagogy. Harvard Educational Review, 64(2), 173-194.

Blackburn, M. V., \& McCready, L. T. (2009). Voices of queer youth in urban schools: Possibilities and limitations. Theory into Practice, 48(3), 222-230.

Castro, A. J. (2010). Themes in the research on preservice teachers' views of cultural diversity: Implications for researching millennial preservice teachers. Educational Researcher, 39(3), 198-210. 
Chizhik, E. W., \& Chizhik, A. W. (2005). Are you privileged or oppressed? Students' conceptions of themselves and others. Urban Education, 40(2), 116-143.

Cochran-Smith, M. (2000). Blind vision: Unlearning racism in teacher education. Harvard Educational Review, 70(2), 157-190.

Cochran-Smith, M., \& Lytle, S. L. (2009). Inquiry as stance: Practitioner research for the next generation. New York, NY: Teachers College Press.

Dabach, D. B., \& Fones, A. (2016). Beyond the "English Learner" frame: Transnational funds of knowledge in social studies. International Journal of Multicultural Education, 18(1), 7-27.

Delgado, R. (2000). Storytelling for oppositionists and others: A plea for narrative. In R. Delgado \& J. Stefancic (Eds.), Critical race theory: The cutting edge ( $2^{\text {nd }}$ ed., pp. 60-70). Philadelphia, PA: Temple University Press.

DiAngelo, R., \& Sensoy, O. (2010). "Ok, I get it! Now tell me how to do it!" Why we can't just tell you how to do critical multicultural education. Multicultural Perspectives, 12(2), 97-102.

Emerson, R. M., Fretz, R. I., \& Shaw, L. L. (2011). Writing ethnographic fieldnotes. Chicago, IL: University of Chicago Press.

Ensign, J. (2009). Multiculturalism in four teacher education programs: For replication or transformation. Multicultural Perspectives, 11(3), 169-173.

Freire, P. (1999). Pedagogy of the oppressed (20 th ed.). New York, NY: The Continuum Publishing Company.

Freire, P., \& Macedo, D. P. (1995). A dialogue: Culture, language and race. Harvard Educational Review, 65(3), 377-402.

Giroux, H. (2011). On critical pedagogy. New York, NY: The Continuum International Publishing Group.

Gonzaléz, N., Moll, L., \& Amanti, C. (Eds.). (2005). Funds of knowledge: Theorizing practices in households, communities and classrooms. New York, NY: Routledge.

Gorski, M. (2009). What we're teaching teachers: An analysis of multicultural teacher education coursework syllabi. Teaching and Teacher Education, 25(2), 309-318.

Gorski, P. (2013). Teaching against essentialism and the "culture of poverty." In P. C. Gorski, K. Zenkov, N. Osei-Kofi, \& J. Sapp (Eds.), Cultivating Social Justice Teachers (pp. 84-100). Sterling, VA: Stylus Publishing.

Gorski, P., Osei-Kofi, N., Zenkov, K., \& Sapp, J. (2013). Introduction. In P. C. Gorski, K. Zenkov, N. Osei-Kofi, \& J. Sapp (Eds.), Cultivating Social Justice Teachers (pp. 1-10). Sterling, VA: Stylus Publishing. 
Grant, C. A., \& Sleeter, C. (2007). Doing multicultural education for equity and achievement. New York, NY: Routledge.

Grant, C. A., \& Sleeter, C. E. (2013). Race, class, gender and disability in the classroom. In J. A. Banks \& C. A. McGee Banks, (Eds.), Multicultural education: Issues and perspectives ( $8^{\text {th }}$ ed.). Hoboken, $\mathrm{NJ}$ : Wiley.

Haviland, V. S. (2008). "Things get glossed over": Rearticulating the silencing power of whiteness in education. Journal of Teacher Education, 59(1), 4054.

Hill, J. (2000). The racializing function of language panics. In González, R., \& Melis, I. (Eds.), Language ideologies: Critical perspectives on the Official English Movement (pp. 245-267). Mahwah, NJ: Lawrence Erlbaum.

Howard, T. C. (2010). Why race and culture matters in schools: Closing the achievement gap in America's classrooms. New York, NY: Teachers College Press.

LaDuke, A. (2009). Resistance and renegotiation: Preservice Teacher interactions with and reactions to multicultural education course content. Multicultural Education, 16(3), 37-44.

Montecinos, C. (2004). Paradoxes in multicultural teacher education research: Students of color positioned as objects while ignored as subjects. International Journal of Qualitative Studies in Education, 17(2), 167-181.

Mthethwa-Sommers, S. (2014). Narratives of social justice educators: Standing firm. New York, NY: Springer.

Nagda, N. A., \& Gurin, P. (2007). Intergroup dialogue: A critical-dialogic approach to learning about difference, inequality, and social justice. New Directions for Teaching and Learning, 111, 35-45.

Nelson, S. W., \& Guerra, P. L. (2015). Educator beliefs and cultural knowledge implications for school improvement efforts. Educational Administration Quarterly, 50(1), 67-95.

Nieto, S. (2003). Profoundly multicultural questions. Educational Leadership, 60(4), 6-10.

Nieto, S., Bode, P., Kang, E., \& Raible, J. (2008). Identity, community and diversity: Retheorizing multicultural curriculum for the postmodern era. In F. M. Connelly, M. F. He, \& J. Phillion (Eds.), The Sage handbook of curriculum and instruction (pp. 176-197). Thousand Oaks, CA: Sage Publications.

Osei-Kofi, N. (2013a). The art of teaching intersectionality. In P. C. Gorski, K. Zenkov, N. Osei-Kofi, \& J. Sapp (Eds.), Cultivating social justice teachers (pp. 11-26). Sterling, VA: Stylus Publishing.

Olser, A., \& Starkey, H. (2005). Education for democratic citizenship: A review of research, policy and practice 1995-2005. London, UK: British Educational Research Association. 
Salazar, M. C., Martinez, L. M., \& Ortega, D. (2016). Sowing the semillas of critical multicultural citizenship for Latina/o undocumented youth: Spaces in school and out of school. International Journal of Multicultural Education, 18(1), 88-106.

Saldaña, J. (2012). The coding manual for qualitative researchers $\left(2^{\text {nd }}\right.$ ed.). Thousand Oaks, CA: Sage.

Shome, R. (1999). Whiteness and the politics of location: Postcolonial reflections. In T. K. Nakayama \& J. N. Martin (Eds.), Whiteness: The communication of social identity (pp. 107-128). Thousand Oaks, CA: Sage.

Sleeter, C. (2008a). Critical family history, identity, and historical memory. Educational Studies: A Journal of the American Educational Studies Association, 43(2), 114-124.

Sleeter, C. (2008b). Preparing White teachers for diverse students. In M. Cochran-Smith, S. Feiman-Nemser, D. J. Mclntyre, \& K. E. Demers, (Eds.), Handbook of research on teacher education: Enduring questions in changing contexts ( $3^{\text {rd }}$ ed.) (pp. 559-583). New York, NY: Routledge.

Solorzano, D. G., \& Yosso, T. J. (2002). Critical race methodology: Counter-story telling as an analytical framework for education. Qualitative Inquiry, 8(1), 23-44.

Sorensen, N., Nagda, B. R. A., Gurin, P., \& Maxwell, K. E. (2009). Taking a "Hands On" approach to diversity in higher education: A Critical-Dialogic Model for effective intergroup interaction. Analyses of Social Issues and Public Policy, 9(1), 3-35.

Valencia, R. (2010). Dismantling contemporary deficit thinking. New York, NY: Routledge.

Valenzuela, A. (1999). Subtractive schooling: U.S.-Mexican youth and the politics of caring. Albany, New York, NY: State University of New York Press.

Vavrus, M. (2002). Transforming the multicultural education of teachers: Theory, research and practice. New York, NY: Teachers College Press.

Vickery, A. E. (2016). "I worry about my community": African American women utilizing communal notions of citizenship in the social studies classroom. International Journal of Multicultural Education, 18(1), 28-44.

Vygotsky, L. (1978). Interaction between learning and development. Readings on the development of children, 23(3), 34-41.

Wells, G. (1999a). Dialogic inquiry: Towards a socio-cultural practice and theory of education. Cambridge, MA: Cambridge University Press.

Wells, G. (1999b). Language and education: Reconceptualizing education as dialogue. Annual Review of Applied Linguistics, 19, 135-155.

Wells, G. (2007). Semiotic mediation, dialogue and the construction of knowledge. Human Development, 50(5), 244-274. 
Wells, G. (2009). The meaning makers: Learning to talk and talking to learn. Towanda, NY: Multilingual Matters.

Williams, D., \& Evans-Winters, V. (2005). The burden of teaching teachers: Memoirs of race discourse in teacher education. The Urban Review, 37(3), 201-219.

\section{Author Contact}

Christina Convertino: cconvertino@utep.edu

University of Texas at El Paso, 500 W. University Ave, EI Paso, TX 79902, USA 